\title{
BMJ Open Clinical decisions presented to patients in hospital encounters: a cross-sectional study using a novel taxonomy
}

\author{
Eirik Hugaas Ofstad, ${ }^{1}$ Jan C Frich, ${ }^{2}$ Edvin Schei, ${ }^{3}$ Richard M Frankel, ${ }^{4}$ \\ Jūratė Šaltytė Benth, ${ }^{5}$ Pål Gulbrandsen ${ }^{1,5}$
}

To cite: Ofstad EH, Frich JC, Schei $\mathrm{E}$, et al. Clinical decisions presented to patients in hospital encounters: a cross-sectional study using a novel taxonomy. BMJ Open 2018;8:e018042. doi:10.1136/ bmjopen-2017-018042

- Prepublication history and additional material for this paper are available online. To view these files, please visit the journal online (http://dx.doi. org/10.1136/bmjopen-2017018042).

EHO and PG contributed equally.

Received 2 June 2017

Revised 16 November 2017

Accepted 24 November 2017

\section{CrossMark}

${ }^{1}$ The Research Centre, Akershus University Hospital, Lorenskog, Norway

${ }^{2}$ Institute of Health and Society, University of Oslo, Oslo, Norway ${ }^{3}$ Department of Global Public Health and Primary Care, University of Bergen, Bergen, Norway

${ }^{4}$ Indiana University School of Medicine, VA HSR and Development Center for Health Information and Communication, Indianapolis, Indiana, USA

${ }^{5}$ Institute of Clinical Medicine, University of Oslo, Lorenskog, Norway

Correspondence to Dr Eirik Hugaas Ofstad; eirikofstad@gmail.com

\section{ABSTRACT}

Objective To identify and classify all clinical decisions that emerged in a sample of patient-physician encounters and compare different categories of decisions across clinical settings and personal characteristics.

Design Cross-sectional descriptive evaluation of hospital encounters videotaped in 2007-2008 using a novel taxonomy to identify and classify clinically relevant decisions (both actions and judgements).

Participants and setting 372 patients and 58 physicians from 17 clinical specialties in ward round (WR), emergency room (ER) and outpatient (OP) encounters in a Norwegian university hospital.

Results The 372 encounters contained 4976 clinically relevant decisions. The average number of decisions per encounter was 13.4 (min-max 2-40, SD 6.8). The overall distribution of the 10 topical categories in all encounters was: defining problem: $30 \%$, evaluating test result: $17 \%$, drug related: $13 \%$, gathering additional information: $10 \%$, contact related: $10 \%$, advice and precaution: $8 \%$, therapeutic procedure related: $5 \%$, deferment: $4 \%$, legal and insurance related: $2 \%$ and treatment goal: $1 \%$. Across three temporal categories, the distribution of decisions was $71 \%$ here-andnow, $16 \%$ preformed and $13 \%$ conditional. On average, there were 15.7 decisions per encounter in internal medicine specialties, 7.1 in

ear-nose-throat encounters and 11.0-13.6 in the remaining specialties. WR encounters contained significantly more drug-related decisions than $\mathrm{OP}$ encounters $(\mathrm{P}=0.031)$ and preformed decisions than ER and OP encounters $(\mathrm{P}<0.001)$. ER encounters contained significantly more gathering additional information decisions than OP and WR encounters $(\mathrm{P}<0.001)$ and fewer problem defining decisions than WR encounters $(P=0.028)$. There was no significant difference in the average number of decisions related to the physician's and patient's age or gender.

Conclusions Patient-physician encounters contain a larger number of clinically relevant decisions than described in previous studies. Comprehensive descriptions of how decisions, both as judgements and actions, are communicated in medical encounters may serve as a first step in assessing clinical practice with respect to efficiency and quality on a provider or system level.

\section{INTRODUCTION}

Decision making is a key activity-perhaps the key activity-in healthcare. ${ }^{1}$ Alvan

\section{Strengths and limitations of this study}

- The study comprises a large material of videorecorded patient-physician encounters including 17 different clinical specialties and three practice settings (outpatients, inpatients on the ward and emergency room).

- Statistical analyses of decisions within various categories were performed by estimating linear mixed models accounting for random and fixed effects to ensure that observed differences were not attributable to significant clustering at doctor level.

- The study was conducted by applying a novel taxonomy that identifies and classifies clinically relevant decisions in a substantially broader way than previous studies describing the number of decisions in medical encounters.

- The encounters were recorded at a single hospital over a limited time period, and the taxonomy has not been tested in general practice or psychiatry.

Feinstein's 1967 harbinger 'Clinical Judgment ${ }^{2}$ spawned a body of research and theory that has advanced the field of decision making in healthcare. ${ }^{13-7}$ Feinstein later concluded $^{8}$ that the field's emphasis on quantitative models derived from non-clinical sources had left central challenges on how decisions are made at the bedside or in the clinic open for pursuit.

In the context of patient-physician encounters, decision-making processes result in diagnoses, choice of treatment, selection of tests, provision of relevant information and scheduling of follow-up-or the decision to do nothing. Traditionally, these decisions have been made by the physician. In recent decades, these decisions-that govern how resources and time are invested in the care of patients-are all under increasing pressure to live up to normative standards like evidence-based medicine (EBM), patient-centred care, patient safety culture and provider professionalism. 
In both research and clinical practice, the focus has often been on single decisions related to a specific context. In EBM, the aim is to formulate an answerable question, search the literature, critically appraise the information and build the decision-making process around best available evidence together with patient values and preferences. ${ }^{9}$ Patient safety programmes select key triggers identifiable as the cause of adverse events, with the aim of flagging them for prescriptive measures. ${ }^{10} 11$ In the context of patient-centred care, decisions are increasingly framed within a shared decision making (SDM) paradigm. Research and implementation of SDM often target single decisions related to a specified, predetermined topic, focusing on difficult decisions with two or more options that patients may weigh differently. ${ }^{12-14}$

Only a handful of studies have attempted to describe the frequency and types of decisions that are made in medical encounters. ${ }^{15-19}$ These studies all aimed to assess the level of patient involvement in decision making. In two of the studies, Braddock et $a l^{15}$ defined a medical decision as 'a verbal statement committing to a particular course of action'. This definition is broad, including actions leading to diagnostic tests, prescriptions, referrals and instructions regarding diet and physical activity. However, it does not capture decisions that govern the subsequent 'courses of action', such as evaluations of findings and tests, and interpretations concerning diagnosis, prognosis and aetiology.

Decision scientists ${ }^{21}$ describe 'problem solving' and 'decision-making' as two separate cognitive processes, and in theory this is a sensible distinction. However, 'problem-solving' in medicine often involves 'decision-making', best illustrated by the fact that diagnostic conclusions seldom reveal themselves, they have to be produced by someone. ${ }^{22}$ Often, the path to diagnostic judgements and therapeutic actions present options that require decision making and, due to both medical and contextual complexity, leave room for interpretation. ${ }^{23}$

Our starting point was that normative and prescriptive approaches to clinical decision making need a descriptive framework for identification and classification of clinical decisions that is precise, detailed and exhaustive. In other words, before one can assess the quality of a clinical decision, one must know what the decision is and what it is based on. In a previous study, we developed a taxonomy for identifying and classifying all clinically relevant decisions, both judgements and actions. ${ }^{24}{ }^{25}$ Building on the work by Braddock $e t a l$, we defined a clinically relevant decision as 'a verbal statement committing to a particular course of clinically relevant action and/or statement concerning the patient's health that carries meaning and weight because it is said by a medical expert.$^{25}$ We applied this definition and the taxonomy to 372 videotaped hospital encounters in order to identify and classify all clinical decisions that emerged in hospital-based patient-physician encounters and to compare different categories of decisions across clinical settings and personal characteristics.

\section{METHODS}

\section{Conceptual framework}

The process of establishing a sensitive definition of a decision in a clinical context, the identification of decisions and the development of a novel taxonomy has been described in detail elsewhere. ${ }^{2425}$ The analytic process was informed by the three prototypical strategies for qualitative research, as described by Crabtree and Miller. ${ }^{26}$ The two fundamental questions describing the core process of the first of the three methods coincide with our initial research questions (in brackets):

- What are the content and constituent elements (of clinically relevant decisions)?

-When does it (a clinically relevant decision) begin?

Our choice to broaden a definition of clinical decisions was based on three criteria: all decisions ${ }^{1}$ must require some element of medical judgement ${ }^{2}$; must relate to the actual patient's concrete situation (ie, are therefore distinct from general medical information); and therefore, ${ }^{3}$ represent important conclusions relevant for the patient to understand and remember, even if not presented as decisions as such. We chose these criteria with the clear aim to describe the medical decisional landscape as it is presented to patients in face-to-face interactions with physicians.

We built a taxonomy with two dimensions: a topical dimension with 10 categories and a temporal dimension with three categories (see table 1). The taxonomy was named DICTUM, or the Decision Identification and Classification Taxonomy for Use in Medicine (a full and updated version of the codebook is available at www. ocher.no/resources/dictum).

\section{Participants}

Available for our study by broad consent were 380 video-recorded patient-physician encounters collected during 2007-2008 as a part of a randomised controlled trial (RCT) to evaluate the effect of a 20-hour communication skills course. ${ }^{27}$ The original RCT comprised 497 encounters, and for 380 of these, both patient and physician provided written consent for the video to be available for other communication studies until 2020. In the remaining 127 encounters, either the patient, the physician or both limited the written consent to the RCT only. The physicians were randomly drawn from all physicians under 60 years of age working in non-psychiatric clinical departments. Patients were recruited consecutively on the days the participating physicians were available. While the patients and physicians gave broad consent to further studies of communication, they were unaware of our subsequent focus on identification and classification of decisions.

\section{Videotape coding}

Analysis of the encounters was done through direct observation of the videotapes. Before formal coding began, we evaluated how consistently we were able to use the taxonomy as a team. Using a maximum variation 
Table 1 The decision identification and classification taxonomy for use in medicine

\section{Topical category Category description}

Example of statement conveying a decision

\begin{tabular}{|c|c|c|c|}
\hline 1 & $\begin{array}{l}\text { Gathering } \\
\text { additional } \\
\text { information }\end{array}$ & $\begin{array}{l}\text { Decision to obtain information from other source than patient } \\
\text { interview, physical examination and patient chart; ordering new } \\
\text { tests/diagnostic procedures for the patient, actively seeking } \\
\text { external information from other party (other hospital, general } \\
\text { practitioner, family member and so on) or discussing patient } \\
\text { with other physician or healthcare personnel. }\end{array}$ & $\begin{array}{l}\text { 'I am going to order an MRI of your } \\
\text { skeleton'. }\end{array}$ \\
\hline 2 & $\begin{array}{l}\text { Evaluating test } \\
\text { result }\end{array}$ & Simple, normative assessments of clinical findings and tests. & $\begin{array}{l}\text { 'Your blood pressure is high. } \\
180 / 100 \text { is high'. }\end{array}$ \\
\hline 3 & Defining problem & $\begin{array}{l}\text { Complex, interpretative assessments that defines what the } \\
\text { problem is and reflects a medically informed conclusion, } \\
\text { thereby being either a diagnostic conclusion, an evaluation } \\
\text { of state of health, an aetiological inference or a prognostic } \\
\text { judgement. }\end{array}$ & $\begin{array}{l}\text { 'This is basically what we call } \\
\text { osteoarthritis'. }\end{array}$ \\
\hline 4 & Drug related & $\begin{array}{l}\text { Decision to start, refrain from, stop, alter or maintain a drug } \\
\text { regimen. }\end{array}$ & $\begin{array}{l}\text { 'I will give you a fourday treatment } \\
\text { of dexametasone'. }\end{array}$ \\
\hline 5 & $\begin{array}{l}\text { Therapeutic } \\
\text { procedure related }\end{array}$ & $\begin{array}{l}\text { Decision to intervene on a medical problem, plan, perform or } \\
\text { refrain from therapeutic procedures of a medical nature. }\end{array}$ & 'We cannot operate more on you'. \\
\hline 6 & $\begin{array}{l}\text { Legal and } \\
\text { insurance related }\end{array}$ & $\begin{array}{l}\text { Medical decision concerning the patient, which is based on or } \\
\text { restricted by a legal regulation or financial arrangements. }\end{array}$ & 'I will write you a sick leave note’. \\
\hline 7 & Contact related & $\begin{array}{l}\text { Decision regarding admittance or discharge from hospital, } \\
\text { scheduling of control and referral to other part of the healthcare } \\
\text { system. }\end{array}$ & $\begin{array}{l}\text { 'She is so weak that she should be } \\
\text { admitted'. }\end{array}$ \\
\hline 8 & $\begin{array}{l}\text { Advice and } \\
\text { precaution }\end{array}$ & $\begin{array}{l}\text { Decision to give the patient advice or precaution, thereby } \\
\text { transferring responsibility for action from provider to patient. }\end{array}$ & $\begin{array}{l}\text { 'You should stop smoking } \\
\text { completely'. }\end{array}$ \\
\hline 9 & Treatment goal & $\begin{array}{l}\text { Decision to set defined goal for treatment and thereby being } \\
\text { more specific than giving advice. }\end{array}$ & $\begin{array}{l}\text { 'We want to get the A1c down } \\
\text { between } 7 \text { and } 8 \text { '. }\end{array}$ \\
\hline 10 & Deferment & $\begin{array}{l}\text { Decision to actively delay decision or a rejection to decide on } \\
\text { problem presented by patient. }\end{array}$ & $\begin{array}{l}\text { 'You have to discuss this with your } \\
\text { family doctor'. }\end{array}$ \\
\hline
\end{tabular}

\section{Temporal category Category description}

Example of statement conveying a decision

\begin{tabular}{llll}
\hline A Preformed & $\begin{array}{l}\text { Decisions that have already been made and are brought into } \\
\text { the encounter by the physician as information. }\end{array}$ & $\begin{array}{l}\text { 'We have started you on some } \\
\text { anticoagulants'. }\end{array}$ \\
B Here-and-now & $\begin{array}{l}\text { Decisions made in the present } \\
\text { 'I will get an ultrasound of your leg } \\
\text { tonight'. }\end{array}$ & $\begin{array}{l}\text { Decisions prescribing future actions given a certain course of } \\
\text { 'If the pills don't alleviate your pain, } \\
\text { you may double the dosage'. }\end{array}$ \\
\hline
\end{tabular}

approach, ${ }^{28}$ we selected sets of five videos from different clinical settings and specialties, with variation in gender and age in both patients and physicians. The four researcher/physicians coded independently, and this process was repeated three times, resulting in minor adjustments to taxonomy categories the first two times and reaching satisfactory consistency on a final version the third time. We tested reliability using Krippendorff's alpha agreement for content coding with multiple coders $^{29}$ and coded a final set of five new videos resulting in a Krippendorff's alpha of 0.79. For coded variables to be reliable, cut-off value for Krippendorff's alpha has been set at $0.80 .{ }^{29}$ Using the categories of the taxonomy, we created a coding scheme in the observation software 'Observer XT' (Noldus Information Technology, Wageningen, The Netherlands). All 372 videos were coded by EHO. Every 20th video was coded independently by PG to check for drift. Two-coder inter-rater reliability was good (Cohen's kappa of 0.61). Intra-rater reliability for EHO, who coded five videos sampled with maximum variation 1 year after the initial coding, was good (Cohen's kappa 0.77).

\section{Statistical analysis}

Once coding was completed, we calculated simple descriptive statistics ${ }^{30}$ using IBM SPSS Statistics V.34. In the analysis, patients and physicians were stratified according to gender, relevant age groups, specialty of physician and type of encounter. The data exhibit hierarchical structure with decisions nested within the doctor and the doctor nested within the specialty. The number of decisions within various categories was thus compared by estimating 
linear mixed models with random effects for doctors nested within specialty or for doctors only. Akaike's information criteria (AIC) ${ }^{31}$ was applied to choose the best model with respect to random effects. The distribution of number of decisions across three temporal categories in three different settings was compared by estimating a linear mixed model with fixed effects for temporal category, setting and interaction between the two. The model assessing the number of decisions within each topical category contained fixed effects for settings. The differences in the average number of decisions between various categories of characteristics of patients and doctors were assessed by first estimating a bivariate linear mixed model for number of decisions with fixed effect for relevant characteristic. Next, a multiple model was estimated. As judged by AIC, a model with random intercepts for doctors only fitted data best, hence specialty was included into the model as a fixed effect instead. All linear mixed models were estimated by SAS MIXED procedure using SAS V.9.4.

\section{RESULTS}

Of 103 invited physicians, $71(69 \%)$ consented to participate in the original trial and $59(57 \%)$ provided broad consent. Of 553 patients approached, $519(94 \%)$ agreed to have their encounter videotaped for the original study and $445(80 \%)$ provided broad consent. ${ }^{32}$ In 65 of the encounters where patients had provided broad consent, the physicians had not, leaving a total corpus of 380 videotaped encounters available for analysis. Of these, eight were excluded from the final analysis: one encounter was incompletely captured (showing only six of $53 \mathrm{~min}$ ), and one physician whose seven encounters all exceeded $90 \mathrm{~min}$ was excluded, as this practitioner represented an extreme outlier. We further analysed 372 videotapes, which contained 4976 decisions. The average number of decisions per encounter was 13.4, min-max 2-40, SD 6.8 .

\section{Characteristics of participants and encounters}

The characteristics of physicians and patients are shown in table 2. The average duration of the 372 encounters was $22 \mathrm{~min}$ (min-max 3-66). In $87(27 \%)$ of 372 of the encounters, communication was observed as challenging either because the patient was a child or an immigrant with limited Norwegian fluency. In three encounters, the patient was a child with immigrant parents with limited Norwegian fluency.

The online appendix table shows that categories 1-19 and 21 of the International Statistical Classification of Diseases and Related Health Problems Revision $10^{33}$ were present in the material, with diseases of the circulatory system (13\%) and neoplasms (10\%) being most frequent. Of the 372 encounters, $81(22 \%)$ contained a clinical procedure comprised by the Norwegian classification of surgical and medical procedures, the most frequent being obstetrical or gynaecological ultrasound (27\%) and echocardiography (21\%)
Table 2 Characteristics of the physicians and patients in our sample*

\begin{tabular}{|c|c|}
\hline & n (\%) \\
\hline \multicolumn{2}{|l|}{ Patients } \\
\hline Men & $182(49)$ \\
\hline Women & $190(51)$ \\
\hline Total & $372(100)$ \\
\hline Age 0-17 years & $81(22)$ \\
\hline Age $18-60$ years & $167(45)$ \\
\hline Age $>60$ years & $124(33)$ \\
\hline Total & $372(100)$ \\
\hline \multicolumn{2}{|l|}{ Physicians } \\
\hline Men & $35(60)$ \\
\hline Women & $23(40)$ \\
\hline Total & $58(100)$ \\
\hline Age $<40$ years & $30(52)$ \\
\hline Age $\geq 40$ years & $28(48)$ \\
\hline Total & $58(100)$ \\
\hline $\begin{array}{l}\text { Internal medicine (cardiology, respiratory } \\
\text { medicine, nephrology, gastroenterology, } \\
\text { endocrinology, haematology, infectious } \\
\text { diseases and oncology) }\end{array}$ & $19(33)$ \\
\hline $\begin{array}{l}\text { Surgery (gastro surgery, urology, thorax } \\
\text { and vascular surgery) }\end{array}$ & 7 (12) \\
\hline Orthopaedics & $5(9)$ \\
\hline Ear-nose-throat & $2(4)$ \\
\hline Anaesthesiology & $3(5)$ \\
\hline Obstetrics and gynaecology & $6(10)$ \\
\hline Paediatrics & $8(14)$ \\
\hline Neurology & $8(14)$ \\
\hline Total & $58(100)$ \\
\hline \multicolumn{2}{|l|}{ Setting } \\
\hline Outpatient & $291(78)$ \\
\hline Ward round & $58(16)$ \\
\hline Emergency room & $23(6)$ \\
\hline Total encounters & $372(100)$ \\
\hline
\end{tabular}

*The 372 patient-physician encounters that was included in our analysis.

\section{Characteristics of clinical decisions}

Table 3 shows the distribution of decisions across the taxonomy's 10 topical categories. The two categories identifying clinical judgements, namely 'defining problem' and 'evaluating test result' together accounted for $47 \%$ of decisions, and were also the two categories present in the largest proportion of encounters $(95 \%$ and $78 \%$, respectively). Decisions categorised as 'drug-related', 'contact-related', 'gathering additional information' or 'advice and precaution' were frequently present in a majority of the encounters. The less frequent categories, 'therapeutic procedure-related' 'deferment', 'legal 
Table 3 Distribution of decisions across 10 topical and three temporal categories, number of encounters with different decision categories present and averages per encounter

\begin{tabular}{llcccc}
\hline & & n (\%) & $\begin{array}{l}\text { Present in number } \\
\text { of encounters (\%) }\end{array}$ & $\begin{array}{l}\text { Average per } \\
\text { encounter }\end{array}$ & Min-max \\
\hline Topical category & & & & \\
\hline 1 & Gathering additional information & $504(10.1)$ & $227(61.0)$ & 1.4 & $0-8$ \\
\hline 2 & Evaluating test result & $829(16.7)$ & $289(77.7)$ & 2.2 & $0-13$ \\
3 & Defining problem & $1512(30.4)$ & $355(95.4)$ & 4.1 & $0-18$ \\
\hline 4 & Drug related & $628(12.6)$ & $223(59.9)$ & 1.7 & $0-10$ \\
\hline 5 & Therapeutic procedure related & $260(5.2)$ & $142(38.2)$ & 0.7 & $0-7$ \\
\hline 6 & Legal and insurance related & $90(1.8)$ & $68(18.3)$ & 0.2 & $0-4$ \\
\hline 7 & Contact related & $496(10.0)$ & $288(77.4)$ & 1.3 & $0-5$ \\
\hline 8 & Advice and precaution & $397(8.0)$ & $205(55.1)$ & 1.1 & $0-8$ \\
\hline 9 & Treatment goal & $70(1.4)$ & $56(15.1)$ & 0.2 & $0-3$ \\
\hline 10 & Deferment & $190(3.8)$ & $129(34.7)$ & 0.5 & $0-5$ \\
\hline & Total & $4976(100)$ & $372(100)$ & 13.4 & $2-40$ \\
\hline Temporal category & & & & $0-22$ \\
\hline A & Preformed & $797(16.0)$ & $213(57.3)$ & 2.1 & $0-31$ \\
\hline B & Here-and-now & $3534(71.0)$ & $371(99.7)$ & 9.5 & $0-9$ \\
\hline C & Conditional & $645(13.0)$ & $277(74.5)$ & 1.7 & $2-40$ \\
\hline
\end{tabular}

and insurance-related' and 'treatment goal', together accounted for $12 \%$ of the decisions but were present in $38 \%, 35 \%, 18 \%$ and $15 \%$ of encounters, respectively.
Table 4 presents the distribution of topical and temporal categories by clinical setting. Decisions made here-and-now were the most frequent in all settings, but as

Table 4 Distribution of topical and temporal decision categories in three different settings

\begin{tabular}{llccc} 
& & Outpatient, $\mathbf{n}(\%)$ & Ward round, $\mathbf{n ~ ( \% ) ~}$ & Emergency room, $\mathbf{n}(\%)$ \\
\hline Total by topical categories & $3905(100)$ & $812(100)$ & $259(100)$ \\
1 & Gathering additional information & $368(9.4)$ & $66(8.1)$ & $70(27.0)^{\star}$ \\
2 & Evaluating test result & $683(17.5)$ & $100(12.3)$ & $46(17.8)$ \\
3 & Defining problem & $1201(30.8)$ & $253(31.2)$ & $58(22.4) \dagger$ \\
4 & Drug related & $438(11.2)$ & $154(19.0) \ddagger$ & $36(13.9)$ \\
5 & Therapeutic procedure related & $216(5.5)$ & $40(4.9)$ & $4(1.5)$ \\
6 & Legal and insurance- related & $67(1.7)$ & $22(2.7)$ & $1(0.4)$ \\
7 & Contact related & $388(9.9)$ & $86(10.6)$ & $22(8.5)$ \\
8 & Advice and precaution & $324(8.3) \S$ & $60(7.4)$ & $13(5.0)$ \\
9 & Treatment goal & $60(1.5)$ & $7(0.9)$ & $3(1.2)$ \\
10 & Deferment & $160(4.4)$ & $24(3.0)$ & $6(2.3)$ \\
\hline Total by temporal categories $\mathbf{n}$ (\%) & $\mathbf{3 9 0 5 ( 1 0 0 )}$ & $\mathbf{8 1 2 ( 1 0 0 )}$ & $\mathbf{2 5 9 ( 1 0 0 )}$ \\
\hline A & Preformed & $456(11.7)$ & $319(39.3) \boldsymbol{\eta}$ & $22(8.5)$ \\
B & Here-and-now & $2921(74.8)$ & $401(49.4)^{* *}$ & $212(81.8)$ \\
C & Conditional & $528(13.5)$ & $92(11.3)$ & $25(9.7)$ \\
\hline
\end{tabular}

${ }^{*}$ Significantly higher than in outpatient $(P<0.001)$ and ward round encounters $(P<0.001)$.

†Significantly lower than in emergency room encounters $(P=0.028)$.

¥Significantly higher than in outpatient encounters $(P=0.031)$.

$\S$ Significantly higher than in emergency room encounters $(P=0.035)$.

ISignificantly higher than in outpatient $(P<0.001)$ and emergency room $(P<0.001)$.

**Significantly lower than in outpatient $(P<0.001)$ and emergency room $(P=0.003)$. 
many as $39.3 \%$ of the decisions conveyed on ward rounds (WRs) had been made before the encounter started. The proportion of preformed decisions was significantly higher in these encounters than in the other two settings $(\mathrm{P}<0.001)$. Emergency room (ER) encounters contained a significantly larger proportion of decisions in the category 'gathering additional information' compared with outpatient $(\mathrm{OP})$ and WR encounters $(\mathrm{P}<0.001)$ and $\mathrm{a}$ significantly smaller proportion of 'defining problem' statements compared with WR encounters $(\mathrm{P}=0.028)$. WR encounters comprised a significantly larger proportion of 'drug-related' decisions than OP encounters $(\mathrm{P}=0.031)$. OP encounters contained a significantly larger proportion of advice and precaution statements than ER encounters $(\mathrm{P}=0.035)$. There were no significant differences in proportions between the three settings in the other topical categories. With regard to temporality, the topical categories 'evaluating test result', 'defining problem' and 'drug-related' accounted for $78 \%$ of the preformed decisions, while 'drug-related', 'contact related', 'advice and precaution' and 'therapeutic procedure-related'-statements made up $77 \%$ of the conditional decisions.

Table 5 shows the average number of decisions per encounter distributed across gender, age, setting and specialty with corresponding 95\% CI According to the multiple linear mixed model, there were no significant differences for patient or physician gender, age or setting. Female physicians communicated 14.7 decisions per encounter, while male physicians communicated $12.7(\mathrm{P}=0.053)$. Compared with internists who had on average 15.7 decisions per encounter, ear-nose-throat (ENT) physicians and obstetrics and gynaecology physicians communicated significantly fewer decisions: 7.1 $(\mathrm{P}=0.006)$ and $11.0 \quad(\mathrm{P}=0.023)$, respectively. Compared with ENT physicians, neurologists and paediatric physicians communicated significantly more decisions: 13.6 $(\mathrm{P}=0.029)$ and $13.4(\mathrm{P}=0.041)$, respectively. Besides internists and ENT physicians, the remaining six groups of hospital specialists had on average between 11.1 and 13.6 decisions. Of the 628 'drug-related' decisions, 299 were found in the 121 internal medicine encounters, meaning an average of $2.5(\mathrm{SD}=2.3)$ 'drug-related' decisions per encounter, compared with an average of $1.3(\mathrm{SD}=1.9)$ in the other specialties combined $(\mathrm{P}=0.002)$.

Figure 1 illustrates the average number of decisions communicated by each physician in their encounters (2-8 encounters per physician). The three physicians who averaged the highest (29.5, 23.5 and 23.3, respectively) were women. The remaining physicians averaged between 6.7 and 20.5 decisions. The range of decisions per encounter varied substantially from physician to physician, the smallest range was $5(9-14)$ and the largest was $29(11-40)$.

\section{DISCUSSION}

We set out to identify and classify all clinically relevant decisions communicated in 372 hospital encounters using
Table 5 Average of decisions per encounter across gender, age, setting and specialty

\begin{tabular}{|c|c|}
\hline & Average $(95 \% \mathrm{Cl})$ \\
\hline \multicolumn{2}{|l|}{ Physicians } \\
\hline Men & $12.7(11.9$ to 13.5$)$ \\
\hline Women & $14.7(13.4$ to 16.0$)$ \\
\hline Age $<40$ years & $13.5(12.5$ to 14.6$)$ \\
\hline Age $\geq 40$ years & $13.2(12.3$ to 14.2$)$ \\
\hline \multicolumn{2}{|l|}{ Patients } \\
\hline Men & $13.2(12.2$ to 14.2$)$ \\
\hline Women & 13.6 (12.6 to 14.5$)$ \\
\hline Age 0-17 years & $12.4(10.8$ to 14.0$)$ \\
\hline Age $18-60$ years & $14.1(13.1$ to 15.2$)$ \\
\hline Age $>60$ years & $13.0(11.9$ to 14.2$)$ \\
\hline \multicolumn{2}{|l|}{ Setting } \\
\hline Outpatient clinic & $13.4(12.6$ to 14.2$)$ \\
\hline Ward round & $14.0(11.9$ to 16.1$)$ \\
\hline Emergency room & $11.3(9.1$ to 13.4$)$ \\
\hline \multicolumn{2}{|l|}{ Specialty } \\
\hline Internal medicine & $15.7(14.5$ to 16.9$)$ \\
\hline Surgery & $12.1(10.4$ to 13.8$)$ \\
\hline Orthopaedics & $12.6(10.5$ to 14.6$)$ \\
\hline Ear-nose-throat (ENT)* & $7.1(4.7$ to 9.6$)$ \\
\hline Anaesthesiology & $11.1(5.1$ to 17.1$)$ \\
\hline Obstetrics and gynaecology $†$ & 11.0 (9.3 to 12.7$)$ \\
\hline Paediatricsł & $13.4(11.2$ to 15.5$)$ \\
\hline Neurology§ & $13.6(11.6$ to 15.5$)$ \\
\hline
\end{tabular}

*Significantly lower than internal medicine $(P=0.006)$.

†Significantly lower than internal medicine $(P=0.023)$.

‡Significantly higher than ENT $(P=0.041)$.

§Significantly higher than ENT ( $\mathrm{P}=0.029)$.

the novel taxonomy DICTUM. ${ }^{24}$ We found that patients, on average, were exposed to more than 13 medically relevant decisions per patient-physician encounter. The encounters in this study were representative of everyday activity in non-psychiatric clinical departments in a large Norwegian hospital. Across topical categories, decisions were diverse; although diagnostic decisions predominated, almost half were of other kinds. Across temporal categories, the majority of decisions were made in the present, but a substantial amount was brought into the encounter as new information, or presented as conditional, depending on future trajectories. With the exception of internal medicine and ENT encounters, we found only minor differences among disciplines. Also, decision frequencies were not associated with patient or physician characteristics. Could this resemblance between specialties and physicians, indicate that DICTUM captures a general structure of how decisions are communicated in medical encounters? 


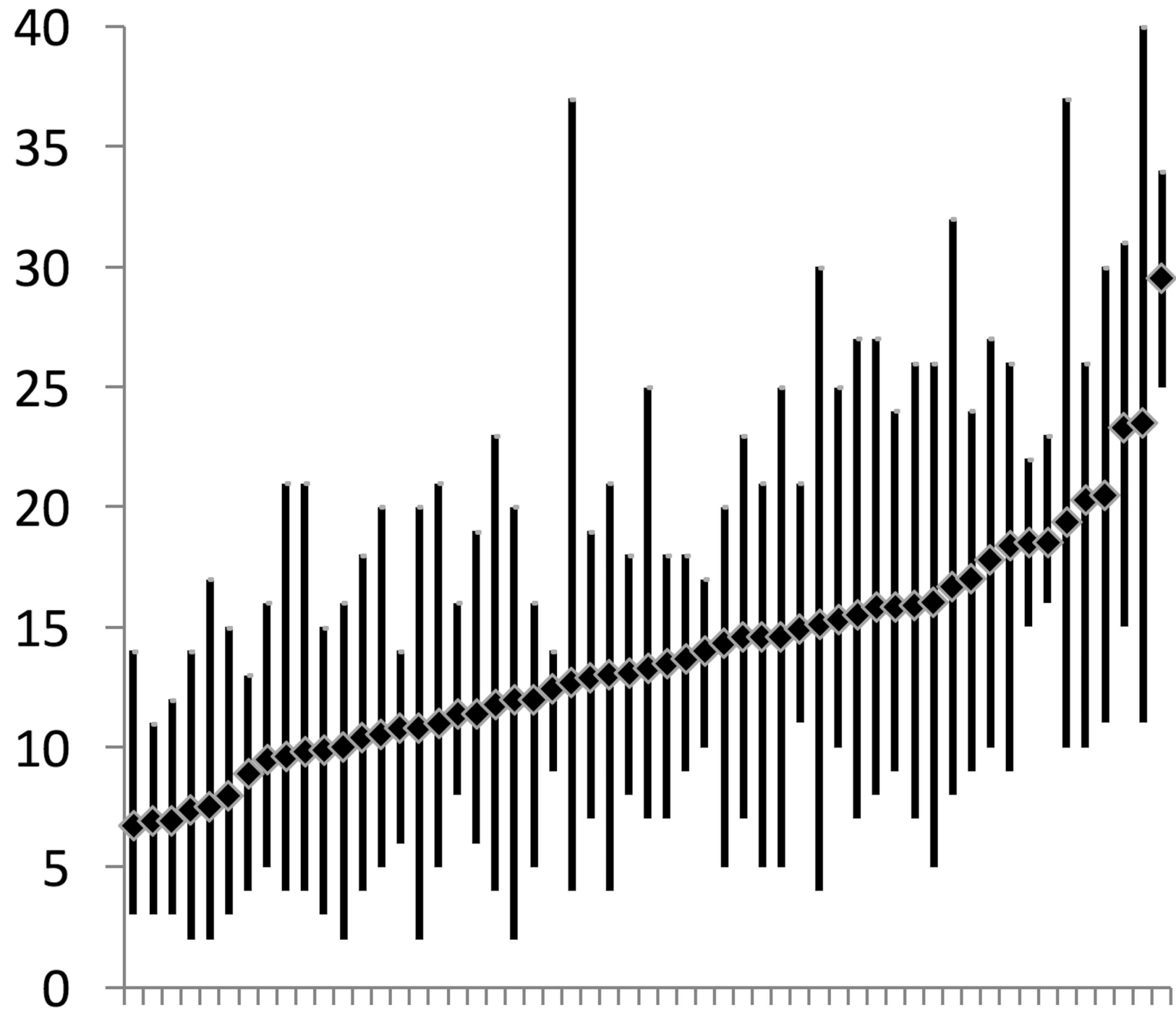

Figure 1 Distribution of frequency of decisions in encounters for each physician. Diamonds indicate average of decisions per physician (interphysician variability). The vertical lines indicate the range for each physician (intraphysician variability). One physician for whom we did only have broad consent for one video is not shown.

Observed differences, for example, a higher frequency of preformed decisions in ward rounds, a lower total frequency in ENT encounters, more 'gathering information' decisions in ER encounters and more 'drug-related' decisions in internal medicine encounters, are all findings that could be expected from these different clinical contexts. WR encounters are commonly preceded by chart review, huddles or formal meetings where providers, either alone or as a team, make judgements and decisions without the patient present. ENT encounters commonly deal with only one concern. In ER encounters, the diagnostic process is at its earliest and gathering additional information through tests or consulting with a colleague or a next of kin is what drives the process forward. Internists deal with more drug-related decisions, partly because their patients often have several previous medications in need of review and partly because diseases cared for by internists frequently have the potential for improvement or prevention through pharmaceutical therapy.
The difference between male and female physicians represents two decisions per encounter; however, this difference was not statistically significant, and we are not convinced that the difference is of clinical significance. On the individual level, however, the averages and ranges of decisions varied greatly and also within disciplines. Illustrated by averages and ranges, respectively, figure 1 shows large interphysician and intraphysician variability: the first possibly reflecting each physician's communication style, and the latter possibly associated with the patient's communication style and the relevant clinical context.

One may challenge our definition of decisions. Previous studies of decisions in patient-physician encounters have reported substantially lower frequencies, varying between on average three and seven decisions per encounter in five different studies. ${ }^{15-19}$ Each of these studies have identified decisions with the aim of describing patient involvement in decisions. These studies did not include diagnostic 
decisions (comprised by our first three categories); if diagnostic decisions are subtracted from our material, our findings align with the findings from previous studies. The inherent elements of medical encounters that we have defined as diagnostic decisions have, in previous studies, been framed as clinical questions that physicians attempt to answer. Ely et al developed a taxonomy of clinical questions to assess how physicians deal with the challenges of treatment, choice of tests and also diagnosis, prognosis and aetiology, by building their framework around clinical questions instead of the judgements and decisions that produce the answers. ${ }^{34}{ }^{35}$ DICTUM may help studies on how physicians and patients deal with and answer these clinical questions in dialogue.

A detailed and exhaustive description of clinical decisions, as they appear to patients in medical encounters, could aid clinical studies and assessments of real-life practice with normative or prescriptive aims. DICTUM offers the possibility of assessing all points in time where decisions are communicated. The basis of diagnoses, aetiology, prognoses, care plans, follow-up, use of time and resources can all be scrutinised with a normative approach on provider or system level. Additional relevant data would be necessary to distinguish between desired standard and substandard medicine. Such data, for example, patient or physician surveys or interviews, patient chart reviews or peer review of encounters, could be collected at the time of decision making and also followed up at a later stage. For inpatient care, an observation framework exceeding the duration of the patient-physician encounter could shed light on which and how decisions are made when the patient is not present-decisions that we in this study observe are presented to patients as information ('preformed decisions').

Introducing physicians and patients to the DICTUM taxonomy before a clinical encounter might affect how decisions are made and communicated. Discussing the observed decisions with physicians and patients after the encounter could provide insight into the lapses in comprehension, meaning and implications of the information shared during the encounter. Providers and institutions strive to deliver high-quality care, increasingly focusing on evidence, patient preferences, safety, efficiency and use of resources. Raising awareness around which decisions need to be made, how they are made and who should make them may not have causal effect on performance, but it would put the punctuation marks of care out in the open.

There are several limitations to our study. The study was conducted applying a novel taxonomy that identifies and classifies clinically relevant decisions in a substantially broader way than previous studies describing the number of decisions in medical encounters.

The taxonomy has not been tested in general practice or psychiatric practice, nor in other hospitals than the one in our study. From an observer perspective, we could not always determine for sure whether the decision had been made before the encounter or was made there and then. In cases where we were in doubt, we coded the decisions as being made in the present. We have studied a videotaped material collected over a limited period of time. Although there may be cultural differences varying over time, between hospitals, regions, countries and how healthcare is financed and legislated, we argue that the taxonomy captures a universal structure of how decisions are communicated in meetings between patients and physicians. Use in other settings is needed to further evaluate the taxonomy's applicability, reliability and validity.

\section{CONCLUSION}

Patient-physician encounters contain a larger number of clinical decisions than described in previous studies. Comprehensive descriptions of how decisions both as judgements and actions are communicated in encounters may serve as a first step in assessing clinical practice with respect to efficiency and quality on a provider or system level.

Acknowledgements We would like to thank Bård Fossli Jensen for recording the majority of the videotaped encounters, and Jennifer Gerwing for her contributions to the final version of the manuscript.

Contributors EHO and PG contributed equally to this study. PG conceived the study and put together the study group. EHO analysed the first 30 videos and selected statements to be discussed in the study group. EHO, JCF, ES and PG took part in all seven group meetings, and all four authors independently analysed the 20 videos for inter-rater reliability measurements. Because of language barrier, RMF did not part take in analysis of the videos, but transcribed and translated statements were presented to RMF during the analytic phase. EHO analysed 372 videos. PG analysed every 20th of these videos to check for inter-rater drift. EHO and PG analysed the data with simple descriptive statistics. JSB performed multilevel statistical analyses. EHO, JCF, ES, RMF, JSB and PG analysed the data and reviewed the manuscript for its intellectual content. All authors had full access to all the data and take responsibility for the integrity of the data and accuracy of the analysis. EHO is guarantor.

Funding This project is funded by South Eastern Norway Regional Health Authority (grant number 2010003).

Disclaimer The funders had no role in study design, data collection and analysis, decision to publish or preparation of the manuscript.

Competing interests None declared.

Ethics approval The study was approved by the Regional Ethics Committee for Medical Research of South-East Norway (1.2009/1415).

Provenance and peer review Not commissioned; externally peer reviewed. Data sharing statement No additional data available.

Open Access This is an Open Access article distributed in accordance with the Creative Commons Attribution Non Commercial (CC BY-NC 4.0) license, which permits others to distribute, remix, adapt, build upon this work non-commercially, and license their derivative works on different terms, provided the original work is properly cited and the use is non-commercial. See: http://creativecommons.org/ licenses/by-nc/4.0/

(C) Article author(s) (or their employer(s) unless otherwise stated in the text of the article) 2018. All rights reserved. No commercial use is permitted unless otherwise expressly granted.

\section{REFERENCES}

1. Schwartz A, Bergus G. Medical decision making: a physician's guide. New York: Cambridge University Press, 2008.

2. Feinstein AR. Clinical judgment. Huntington: R.E Krieger Pub. Co, 1974. 
3. Dowie J, Elstein AS. Professional judgment: a reader in clinical decision making. New York: Cambridge University Press, 1988.

4. Wulff HR, Gøtzche PC. Rational diagnosis and treatment: evidencebased clinical decision-making. Malden, MA: Blackwell Science, 2000.

5. Chapman GB, Sonnenberg FA. Decision making in health care: theory, psychology, and applications. New York: Cambridge: University Press, 2000.

6. Hunink MGM, Glasziou P, Siegel J, et al. Decision making in health and medicine: integrating evidence and values. New York: Cambridge University Press, 2001.

7. In: Gigerenzer G, Muir Gray JA, eds. Better doctors, better patients, better decisions: envisioning health care 2020. Cambridge: MIT Press, 2013.

8. Feinstein AR. "Clinical Judgment" revisited: the distraction of quantitative models. Ann Intern Med 1994;120:799-805.

9. Straus SE. Evidence-based medicine: how to practice and teach it. Evidence-based medicine: how to practice and teach it. Edinburgh: Elsevier Churchill Livingstone, 2011.

10. Michel P, Quenon JL, de Sarasqueta AM, et al. Comparison of three methods for estimating rates of adverse events and rates of preventable adverse events in acute care hospitals. BMJ 2004;328:199.

11. Parry G, Cline A, Goldmann D, et al. Deciphering harm measurement JAMA 2012;307:2155-6.

12. Stacey D, Légaré F, Col NF, et al. Decision aids for people facing health treatment or screening decisions. Cochrane Database Syst Rev 2014;1:CD001431.

13. Elwyn G, Edwards A, Wensing M, et al. Shared decision making observed in clinical practice: visual displays of communication sequence and patterns. J Eval Clin Pract 2001;7:211-21.

14. Braddock C, Hudak PL, Feldman JJ, et al. "Surgery is certainly one good option": quality and time-efficiency of informed decisionmaking in surgery. J Bone Joint Surg Am 2008;90:1830-8.

15. Braddock $\mathrm{CH}$, Fihn SD, Levinson W, et al. How doctors and patients discuss routine clinical decisions. Informed decision making in the outpatient setting. J Gen Intern Med 1997;12:339-45.

16. Braddock $\mathrm{CH}$, Edwards $\mathrm{KA}$, Hasenberg NM, et al. Informed decision making in outpatient practice: time to get back to basics. JAMA 1999;282:2313-20.

17. Saba GW, Wong ST, Schillinger D, et al. Shared decision making and the experience of partnership in primary care. Ann Fam Med 2006;4:54-62.

18. Hauer KE, Fernandez A, Teherani A, et al. Assessment of medical students' shared decision-making in standardized patient encounters. J Gen Intern Med 2011;26:367-72.
19. Clayman ML, Makoul G, Harper MM, et al. Development of a shared decision making coding system for analysis of patient-healthcare provider encounters. Patient Educ Couns 2012;88:367-72

20. Elstein AS, Schwartz A, Schwarz A. Clinical problem solving and diagnostic decision making: selective review of the cognitive literature. BMJ 2002;324:729-32.

21. Deber RB. Physicians in health care management: 8 . The patientphysician partnership: decision making, problem solving and the desire to participate. CMAJ 1994;151:423-7.

22. Måseide $P$. The deep play of medicine: discursive and collaborative processing of evidence in medical problem solving. Commun Med 2006;3:43-54.

23. Norman G. Research in clinical reasoning: past history and current trends. Med Educ 2005;39:418-27.

24. Ofstad EH, Frich JC, Schei E, et al. What is a medical decision? A taxonomy based on physician statements in hospital encounters: a qualitative study. BMJ Open 2016;6:e010098.

25. Ofstad EH, Frich JC, Schei E, et al. Temporal characteristics of decisions in hospital encounters: a threshold for shared decision making? A qualitative study. Patient Educ Couns 2014;97:216-22.

26. Crabtree BF, Miller WL. Doing qualitative research. 2nd edn. Thousand Oaks:CA: Sage Publications, 1999.

27. Fossli Jensen B, Gulbrandsen P, Dahl FA, et al. Effectiveness of a short course in clinical communication skills for hospital doctors: results of a crossover randomized controlled trial (ISRCTN22153332). Patient Educ Couns 2011;84:163-9.

28. Kuper A, Lingard L, Levinson W. Critically appraising qualitative research. BMJ 2008;337:a1035.

29. Krippendorff KH. Content Analysis. An Introduction to its methodology. 3rd edn. Thousand Oaks: SAGE Publications, 2013.

30. Altman DG. Practical statistics for medical research. Practical statistics for medical research. Boca Raton: Chapman \& Hall/CRC 1999.

31. Akaike $\mathrm{H}$. A new look at the statistical model identification. IEEE Trans Automat Contr 1974;19:716-23.

32. Gulbrandsen P, Jensen BF. Post-recruitment confirmation of informed consent by SMS. J Med Ethics 2010;36:126-8.

33. Anon. The International statistical classification of diseases and related health problems (ICD-10). Geneva: World Health Organization, 2004.

34. Ely JW, Osheroff JA, Gorman PN, et al. A taxonomy of generic clinical questions: classification study. BMJ 2000;321:429-32.

35. Del Fiol G, Workman TE, Gorman PN. Clinical questions raised by clinicians at the point of care: a systematic review. JAMA Intern Med $2014 ; 174: 710-8$ 